\title{
A Home Power Aware System
}

\author{
Shangyuan Chen* and Zhenlun Hu \\ Department of Architecture \\ Feng Chia University \\ No. 100, Wenhwa Rd., Seatwen, Taichung, Taiwan 4072 \\ *Corresponding author
}

\begin{abstract}
Because of the development of a smart grid and smart meter infrastructure, smart homes can use various energy management approaches. This study proposes the use of a Home Power Aware System (HPAS) and intuitive user interface to help household occupants to be aware of the state of electricity use involving different types of power generation and unconsciously improve their electrical use behavior, and thereby achieve the goal of reducing mains electricity consumption.
\end{abstract}

Keywords-context-awareness; intuitive design; energy efficiency; NI DAQ data acquisition; LabVIEW software

\section{INTRODUCTION}

In line with the concepts of environmental protection and energy conservation, most of the world's leading countries are concurrently implementing smart grid projects in hopes of using and managing energy in a more effective manner. Apart from this, encouraging consumers' use of various forms of distributed power generation, and reducing their use of mains electricity, is an important pathway toward a nuclear-free homeland. Because of this, the development of a home power aware system (HPAS) that occupants can easily understand, and which encourage occupants to make the best use of electricity, involving different types of power generation, has become an important research topic.

\section{LITERATURE REVIEW AND CASE STUDIES}

Most of the home energy management system (HEMS) on the market emphasizes the monitoring and control of consumer energy uses, but fails to express the distribution, form various power sources on the smart grid. A Home Power Aware System (HPAS) can be defined as an awareness system under a smart grid and smart meter infrastructure aimed at household members, has the goal of providing home users clear and easily-understood reminders of power supply, form various power sources (including alternative energy, energy storage, and mains electricity), for the purpose of reducing mains electricity consumption, therefore encouraging users to unconsciously improve their power use habits.

A HPAS studies overlaps with the scope of a smart grid and energy management, and encompasses research dimensions including energy management policy, algorithms, smart grid systems and technology, energy management systems and technology, and home energy management systems and technology.

A "smart grid" has been defined as the use of automatic monitoring and control technologies, in conjunction with information and communications technology, to assist effective grid operational planning and strengthen user participation, and combines an electric power system with information and communications technology and services to achieve the goals of energy conservation and reduction in carbon emissions [1, 2]. In a smart grid facility, on the demand side, information expressing the status of various power sources can be actively provided to consumers via an Energy Management System (EMS), the development of this system represents an important new challenge [3].

According to Yang (2008) [4], Building and Energy Management System (BEMS) applications have been developed since 1955. Nevertheless, to date, from both academic and practical viewpoints, the development of intelligent home energy management systems in a smart grid infrastructure is still at an extremely early stage.

Researchers have submitted various mathematical models and algorithms to describe the differences in the management of conventional centralized and distributed power supply systems. Mohsenian-Rad, A.-H. et al. (2010) suggests that distributed power in the form of smart grids is an optimal energy conservation strategy, and will enable the achievement of Nash equilibrium [5]. Khanna (2012) believes that the incorporation of unpredictable renewable energy in power grids will prompt the development of wide area control algorithms [6].

Apart from this, other researchers have explored the use of information and communication technologies, such as wireless transmission equipment in power monitoring and control systems [7].

A home energy management system is an energy management system aimed at household users, and includes energy supply, consumption, management, storage, and energy cycle management mechanisms. Wang (2013) explained a home energy management system as employing various information and communications technologies to sense and collect information on energy use by household occupants, and relying on analysis of power use behavior to provide optimized energy conservation measures to guide home energy management. The realization of such a system will require the development of visualization technology, automation and control technology, and analytical functions [8].

At the level of practical applications, according to NRGExpert (2011), home energy management systems are still at a very early stage in terms of development and applications [9]. Because the distributed power system concept and technologies such as smart grids, smart meters, and smart appliances are still far from ubiquitous, most consumers naturally do not know how to make the best use of the tools 
they provide to monitor their power use. As a result, for example, the Google Power Meter product was discontinued after two years of promotion. Table I. summarizes three existing, online home energy monitoring and control tools on the market.

The foregoing review of the literature and case analysis reveals that online energy monitoring and management tools rely on smart meters as power information sensing elements, and employ wireless communications technology, computer processing capacity, and control technology to monitor and analyze power usage. Existing home energy management systems emphasize user-end power consumption, and are able to analyze power use. Nevertheless, there is as yet little understanding of distributed power supply models and applications methods in a smart grid/smart meter infrastructure. In order to encourage consumers to use various forms of distributed power generation and reduce their dependence on mains electricity, system and interface development must place particular emphasis on the provision of power supply information. As a consequence, on the demand side, the development of a home power aware system that can actively provide information on various power sources to users, and can give users easily-understood, useful information, is a key new challenge.

\section{TABLE I. OVERVIEW OF HOME ENERGY MONITORING TOOLS}

\begin{tabular}{|c|c|c|c|}
\hline Item & $\begin{array}{c}\text { Google Power Meter monitoring interface } \\
{[10]}\end{array}$ & Microsoft Hohm monitoring interface [11] & $\begin{array}{c}\text { San Der Technology's ASENs-910 series } \\
{[12]}\end{array}$ \\
\hline Image & 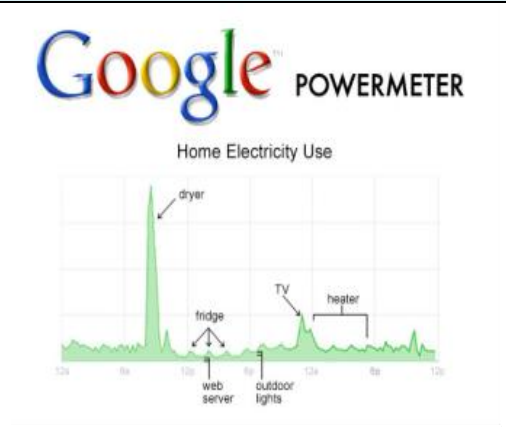 & Sohviz & 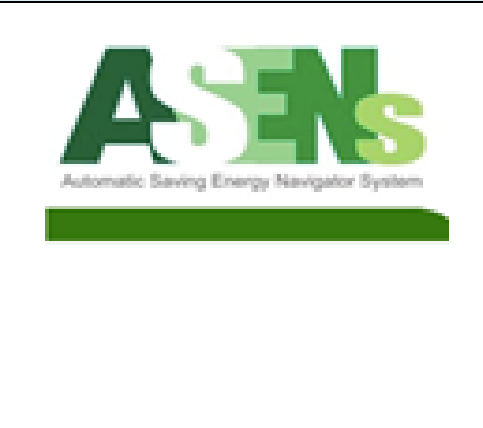 \\
\hline Time available & $2009 / 02-2011 / 09$ & June $24,2009-2012$ & Unclear date - until Now \\
\hline Explanation & $\begin{array}{l}\text { Consumers can use smart meters and } \\
\text { energy devices to observe the real-time } \\
\text { power use of household equipment via the } \\
\text { Internet. }\end{array}$ & $\begin{array}{l}\text { Microsoft Hohm has functions similar to those } \\
\text { of the Google PowerMeter, but is also able to } \\
\text { compare and analyze the power consumption } \\
\text { of households with similar size and areas, } \\
\text { which helps it to provide power-saving } \\
\text { recommendations. }\end{array}$ & $\begin{array}{l}\text { Using Zigbee wireless transmission } \\
\text { technology, smart meters can view current } \\
\text { power information in real-time via the } \\
\text { Internet, and allow users to query } \\
\text { historical data and statistics, including } \\
\text { daily/monthly power consumption and } \\
\text { maximum demand. }\end{array}$ \\
\hline Restrictions & $\begin{array}{l}\text { The interface displays the power usage of } \\
\text { household equipment. However, consumers } \\
\text { cannot easily distinguish good and bad } \\
\text { power consumption. In other words, } \\
\text { consumers not only need information, but } \\
\text { also need to know how to interpret it. }\end{array}$ & $\begin{array}{l}\text { The interface emphasizes consumer power use } \\
\text { behavior, but fails to express the distribution } \\
\text { and usage of various power sources on the } \\
\text { smart grid. It is still chiefly oriented toward } \\
\text { consumers using mains electricity. }\end{array}$ & $\begin{array}{l}\text { Chiefly uses tables, statistics, and } \\
\text { analytical charts to express data, and } \\
\text { employs much opaque jargon. As a result, } \\
\text { a specialist is required to determine users' } \\
\text { power load and use problems on the basis } \\
\text { of historical data. }\end{array}$ \\
\hline
\end{tabular}

\section{THEORY AND METHOD}

To encourage consumers' use of various forms of distributed power generation (including alternative energy and energy storage), and reduce their consumption of mains electricity, this study advocates the development of a Home power aware system (HPAS) and user interface possessing the features of context-awareness, intuitive design, and energy efficiency. By ensuring that household occupants can easily understand the power supply status, a HPAS can encourage users to improve their energy usage. Figure I shows the structure of a HPAS with context-awareness. In accordance with its mission of energy conservation and cost reduction, this system provides an intuitive interface displaying real-time power usage in a form that is easy for users to see and understand. As a result, the HPAS can encourage household occupants to improve their power use behavior, and thereby improve the power supply situation. Because of this, use of a HPAS will promote more efficient energy use. In the HPAS, power supply information is sensed and updated at intervals, and the system operates in a cyclic manner. The following is an explanation of the system's features of context-awareness, intuitive design, and energy efficiency. 


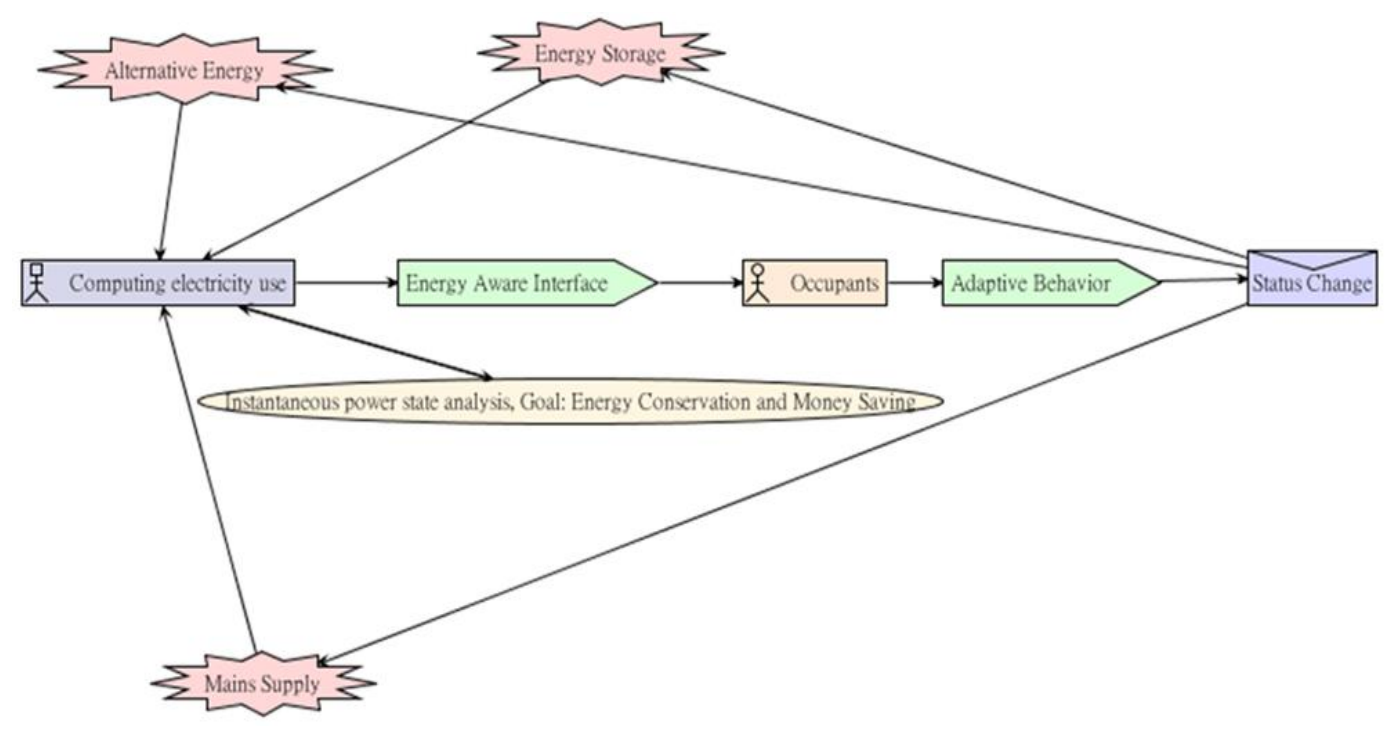

FIGURE I. A HPAS ARCHITECTURE

\section{A. Context-Awareness}

Context-awareness implies the use of contextual information. A context-aware system is able to extract, interpret, and use contextual information, adjust its functions, and the context produced in real-time can then be reused [13, 14, and 15]

\section{B. Intuitive Design}

The most important factor in an intuitive product design is to minimize as much as possible the gap between users' current knowledge or natural tendencies and the target knowledge needed to use the product to perform a task [16]. A product or user interface intended to cause users to change their behaviours can be explained using the Forging Behaviour Model (FBM), which is in widespread use among designers. According to this model, the product should be able to provide sufficient motivation, have actions that can be implemented, and can trigger the implementation of actions [17].

$$
\text { Behaviour }=\text { Motivation } \times \text { Ability } \times \text { Trigger }
$$

\section{Energy Efficiency}

A HPAS pursues energy efficiency in order to achieve the goal of energy conservation and monetary savings. Patterson (1996) [18] broadly defined energy as:

$$
\text { Energy efficiency }=\frac{\text { Useful output of a process }}{\text { Energy input of a process }}
$$

With regard to power sources providing power to the home, in view of the need for environmental protection and economy, alternative energy should take precedence over energy storage, and energy storage should take precedence over mains electricity. Since using mains electricity, in particular, requires pay power fees, it is the chief concern of household occupants. Because of this, avoidance of the use of costly mains electricity can serve to trigger users' motivation to change their behaviours. In other words, good energy efficiency can be achieved if household occupants are able to obtain relatively large amounts of electricity services while paying relatively low electricity fees during a particular power supply period (such as through the use of alternative energy and energy storage as much as possible).

Furthermore, because power bills are incurred only when mains electricity is used, the formula used to calculate household energy efficiency can be simplified as the ratio of an organization's total power consumption to the mains electricity used during the same period. Therefore, the diagram of "Energy Efficiency" is as Figure II:

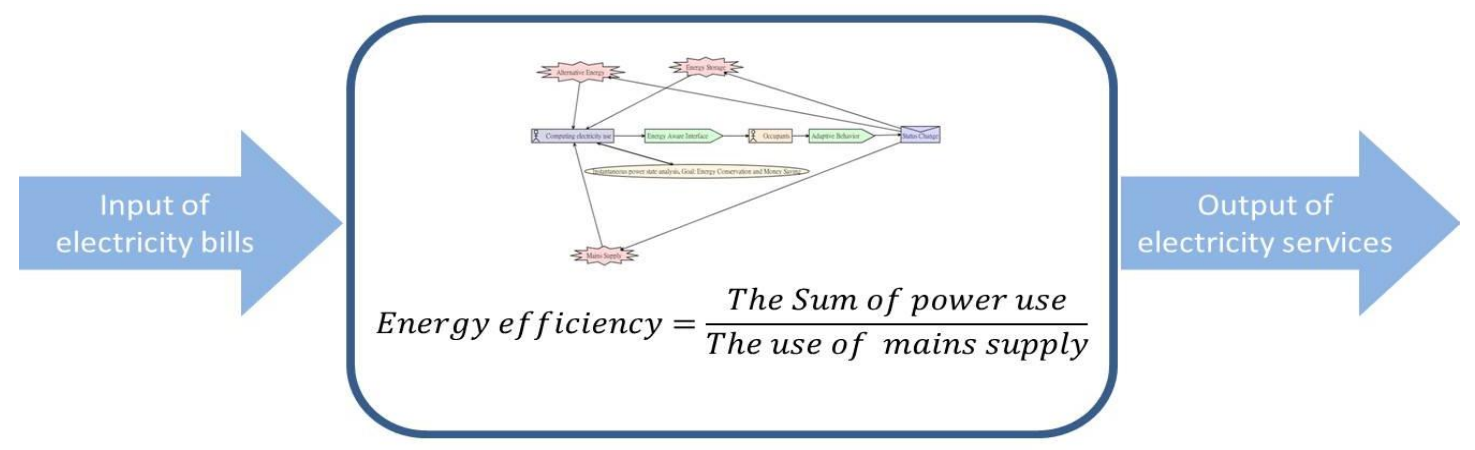

FIGURE II. DIAGRAM OF "ENERGY EFFICIENCY” 


\section{PRATICAL VERIFICATION}

Taking advantage of the solar panels and two wind turbines already installed on the roof of Feng Chia University's Science and Aeronautical Engineering Building, this project plans to establish a demonstration wall in a classroom on the 9th floor. The demonstration area will have a home energy aware interface displaying the supply and use of various types of energy (including alternative energy, power from energy storage batteries, mains electricity). As shown in Figure III, energy supply data obtained via a data acquisition card is analyzed using a computer, and the interface provides four different power supply information reminder modes to inform users of the current power supply situation. The intuitive user interface encourages occupants to change their power use behaviors in accordance with the state of the power supply, enabling users to pursue energy efficiency and achieve the goal of energy conservation and monetary savings. And shown in Figure IV is the exhibition room and the HPAS demonstrated monitor on the wall. At the technological level, the HPAS and its user interface are constructed using (1) NI DAQ energy data acquisition equipment and (2) LabVIEW interface writing software. The HPAS data acquisition and analysis are performed using the following hardware and software: data acquisition card, enclosures for equipment, computer processor or controller, and interface reading and writing software (Figure V). This study uses a NI DAQ data acquisition card, this system possesses multiple data monitoring terminals, and can simultaneously monitor multiple forms of energy. In this study, the system comprises the power data acquisition end. The data acquisition card has nine input terminals and can read data from nine sources, the signals are passed through a power operational amplifier and low-noise operational amplifier, and a modem operates on the passing power flow. Data transmitted from the acquisition card currently enters an existing electric meter instrument panel to provide a preliminary information display, and the data is then transmitted to a computer/controller, where data analysis is performed by using LabVIEW software.

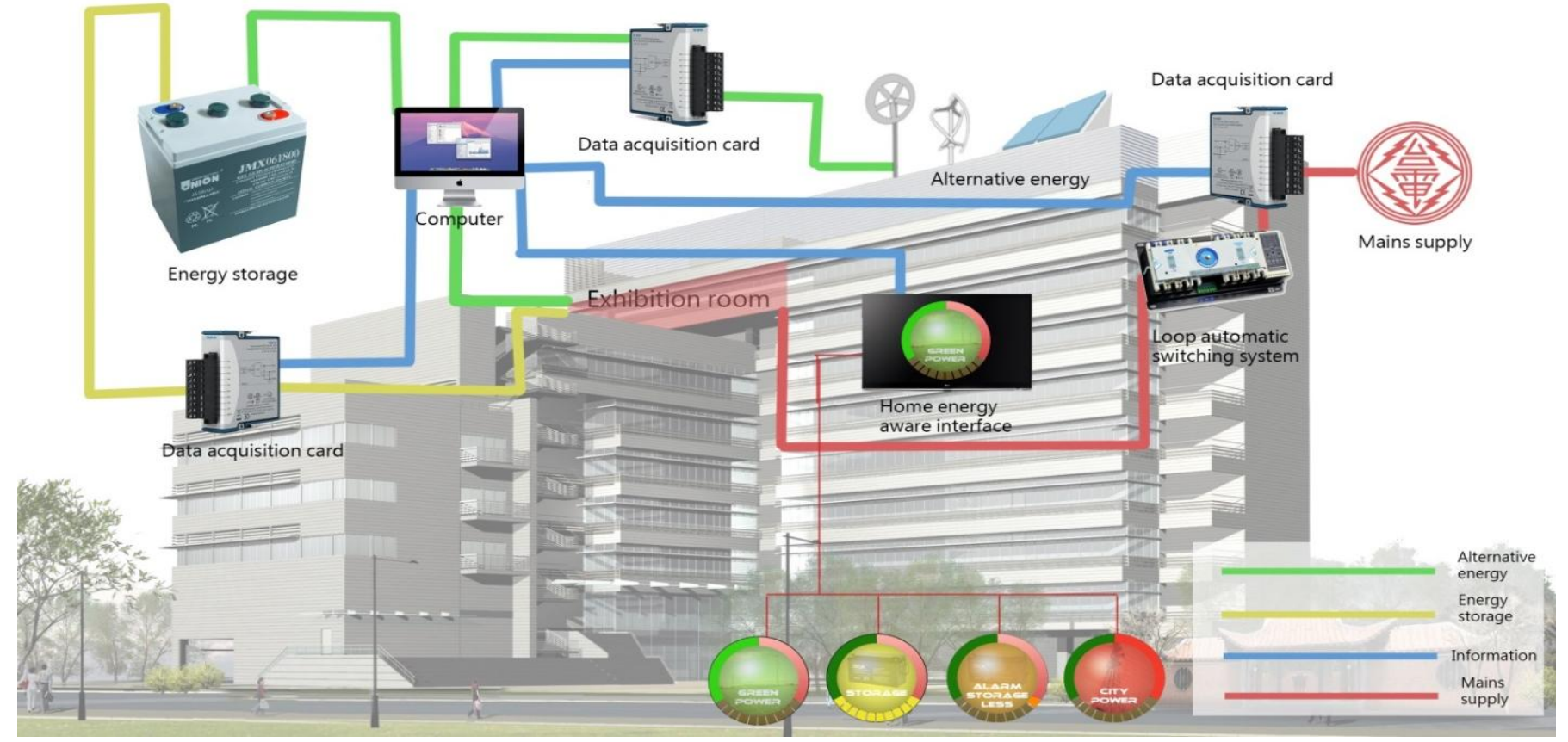

FIGURE III. BUILDING A HPAS

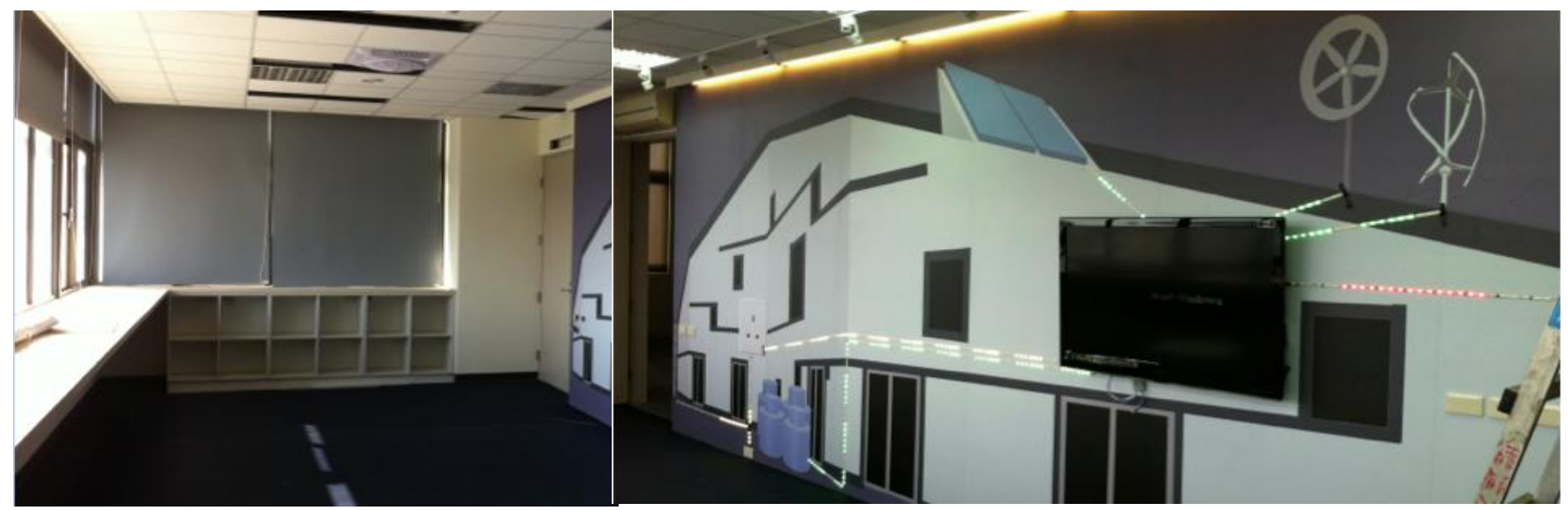

FIGURE IV. THE EXHIBITION ROOM AND THE HPAS DEMONSTRATED MONITOR ON THE WALL 


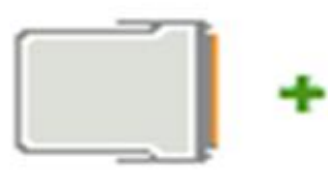

Data-acquisition card

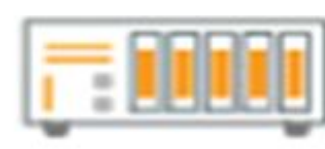

$$
\begin{gathered}
\text { Enclosures for } \\
\text { equipment }
\end{gathered}
$$

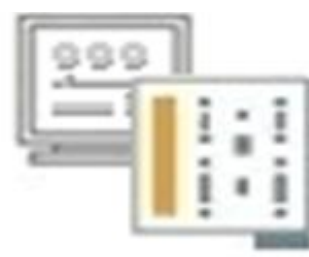

Computer/Controller

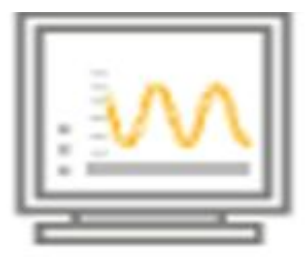

Software

FIGURE V. DATA ACQUISITION AND ANALYSIS EQUIPMENT

The home energy aware interface's analysis software was written using the LabVIEW graphic interface writing software, the syntax contains five parts: (Figure V)

(1) Element controller

(2) While loop

(3) Local variable display

(4) For loop

(5) User interface

The display of the image library and current image depends on the "if and then" results of the while loop and for loop. The following is an example:

Set $\mathrm{P}$ as the percentage of power from alternative energy and stored energy.

In steps $1-3$, when $P=100$, there is a sufficient supply of alternative energy, the EB1 image appears when the value of Op is 1 , which indicates that power consists of alternative energy.

In steps $4-6$, when $\mathrm{P}=0$, this indicates that there is no power from storage or green energy. At this time, all power will consist of mains electricity. The EB13 image will appear when the value of $\mathrm{Op}$ is 2 , indicating that the power is supplied by mains electricity.
In steps $7-9$, when $\mathrm{P}<20$, power from energy storage is insufficient to handle the load, the EB2 image will appear when the out value is 2, and comprises an energy storage low warning indicator.

In steps $10-12$, when $\mathrm{P}=99-20$ (else), this indicates that most power is being supplied from storage. Depending on the percentage, the indicators EB3-EB12 will appear when the out value is 11 , indicating that power is being supplied from storage, ten equal intervals are used to display the amount of power in storage.

The display interface uses color to indicate the real-time power supply situation in an intuitive manner. The interface design uses the three colors green, yellow, and red to indicate alternative energy, stored energy, and mains electricity. The results of analysis are expressed in the form of four modes: (1) alternative energy supply mode, (2) energy supply from storage batteries mode, (3) low storage battery power warning mode, and (4) mains electricity power supply mode, which notify users of the current state of power supply (Figure V). The highly intuitive user interface encourages household occupants to pursue energy efficiency via intuitive thinking, prompting them to unconsciously change their power use habits so as to achieve the goal of energy conservation. (Figure VII).

\section{(2) While loop}

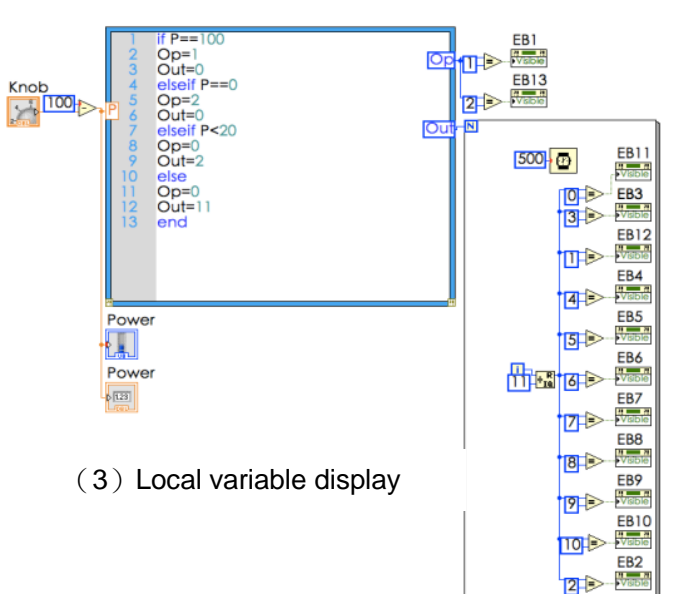

(4) For loop
(5) User Interface

FIGURE VI. RESULTS OF ANALYSIS EMPLOYING A HOME POWERE AWARE INTERFACE WRITTEN USING LABVIEW 


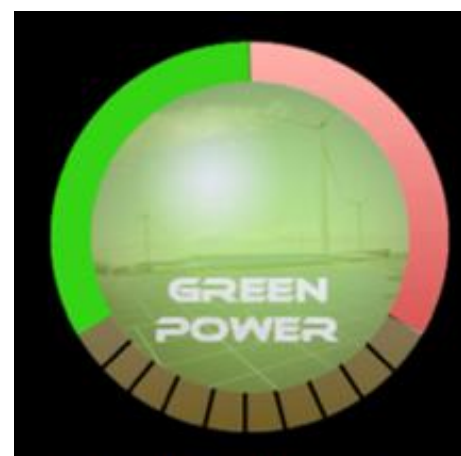

(1)-Alternative energy

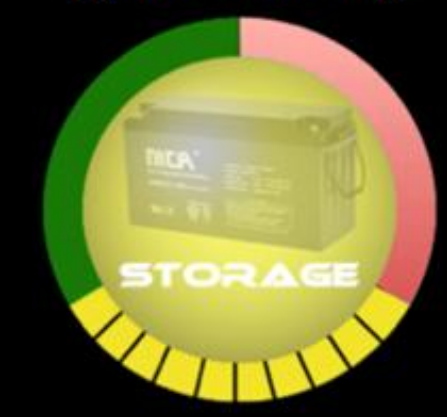

(2) Storage batteries

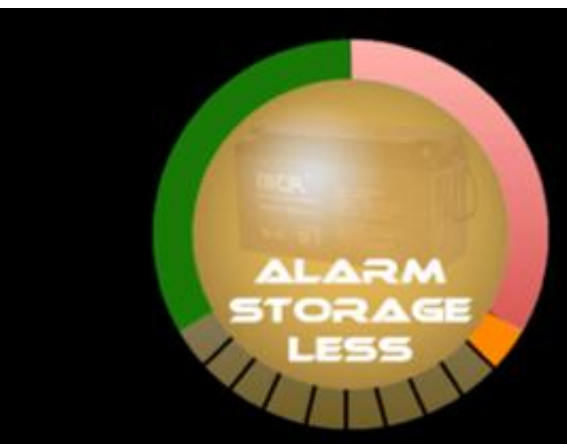

(3) Power in storage batteries low-

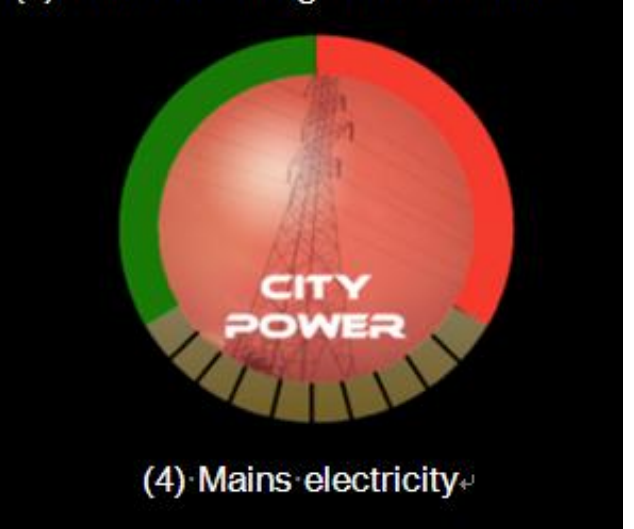

(4)-Mains electricity

FIGURE VII. FOUR DIFFERENT MODES IN HOME POWER AWARE INTERFACE

\section{CONCLUSIONS}

This study examined the theory and methods concerning home energy aware system, and employed a practical model to examine the feasibility of such a system. Recommendations and discussion are as follows:

(1) Use of a HPAS as an auxiliary element of a Home Energy Management System:

In view of the fact that household members typically very concerned about their electrical bills, this study designed a home power aware system. However, although it cannot yet display power usage by household appliances and equipment, this system can be usefully employed as an auxiliary element in a Home Energy Management System (HEMS). In this configuration, when users analyze power usage, they will think about how they can change the use of household equipment in order to reduce their electrical charges.

(2) Complexity of power supply and demand:

It is possible to control power supply and demand in the laboratory, and sequentially apply alternative energy, energy from storage, and mains electricity. However, load data for a real household maybe difficult to subject to batch processing. For instance, at times of peak consumption, when household load is large, power may simultaneously come from alternative energy, storage batteries, and mains electricity.

\section{REFERENCES}

[1] Kaplan, S.M., Sissine, F., Smart Grid, TheCapitol.Net, 2009, pp124-167

[2] Gellings, C.W., The Smart Grid: Enabling Energy Efficiency and Demand Response, The Fairmont Press, Inc., 2009, pp.1-88
[3] Vi-jayapriya, T., et al., Smart Grid: An Overview, Smart Grid and Renewable Energy, 2011, 2, 305-311

[4] Yang, K.H., Building Energy Management (BEMS) handbook, Taiwan Green Productivity Foundation, 2008, Available online: http://www.ecct.org.tw/print/files/971230\%E5\%BB\%BA\%E7\%AF\%89 $\%$ E8\%83\%BD\%E6\%BA\%90\%E7\%AE\%A1\%E7\%90\%86(BEMS)\%E7 \%AF\%80\%E8\%83\%BD\%E6\%89\%8B\%E5\%86\%8A.pdf, (19/07/2015)

[5] Mohsenian-Rad, A.-H., et al., Autonomous Demand-Side Management Based on Game-Theoretic Energy Consumption Scheduling for the Future Smart Grid, Smart Grid, IEEE Transactions on, 2010, (Volume:1, Issue: 3 )

[6] Khanna, A., Smart Grid, Smart Controllers and Home Energy Automation-Creating the Infrastructure for Future, Smart Grid and Renewable Energy, 2012, 3, 165-174

[7] Sultan, S., et al., A New Technology of Online-Condition Monitoring of Energy Conservation Generation \& Loads, Smart Grid and Renewable Energy, 2013, 4, 18-22

[8] Wang, Y.Z., Home energy management systems development analysis, Market Intelligence \& Consulting Institute, MIC, Channel, 2013, Available online:, http://mic.iii.org.tw/channelmic/channel_detail.asp? cno=199\&ccate $=\mathrm{CH}$ AN, (19/07/2015)

[9] NRGExpert, Global Smart Grid Report- Market Research, 2011

[10] Google PowerMeter monitoring interface, Available online: www.google.com/powermeter/ , (23/03/2011)

[11] Microsoft Hohm monitoring interface, Available online: www.microsoft-hohm.com , (23/03/2011)

[12] San Der Technology ASENs-910 series, smart meter and cloud real-time monitoring interface system, Available online: http: //www.asens.com/index.php? act=prod\&opl=43, (19/07/2015)

[13] Weiser, M., The Computer of the 21st Century, Scientific American, 1991, 265 (3), pp. 66 75.

[14] Schilt, B., Adamsn, N., Want, R., Context-Aware Computing Applications, Proceedings of the 1st International Workshop on Mobile Computing Systems and Applications, 1994,pp. 85 90 
[15] Dey, A.K., Abowd, G.D., Toward a better understanding of context and context-awareness. GVU Technical Report GIT-GVU-99-22, College of Computing, Georgia Institute of Technology, 1999, Available online: ftp://ftp.cc.gatech.edu/pub/gvu/tr/1999/99-22.pdf, (19/07/2015)

[16] Spool, J.M., What Makes a Design Seem 'Intuitive'?, User interface Engineering, 2005, Available https://www.uie.com/articles/design_intuitive/, (19/07/2015)

[17] Fogg, B.J., A behavior model for persuasive design, Persuasive '09 Proceedings of the 4th International Conference on Persuasive Technology, 2009, Article No. 40

[18] Patterson, M.G., "What is Energy Efficiency? Concepts, Indicators and Methodological Issues," Energy Policy, 1996, 24:5, 377-390. 